\title{
NONLINEAR SPILLOVER EFFECT OF US MONETARY POLICY UNCERTAINTY ON CHINA'S SYSTEMATIC FINANCIAL RISKS
}

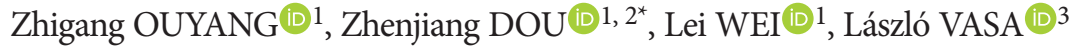 \\ ${ }^{1}$ School of Finance, Zhongnan University of Economics and Law, Wuhan, China \\ ${ }^{2}$ School of Business, Hunan University of Humanities, Science and Technology, Hunan, China \\ ${ }^{3}$ School of Business and Economics, Széchenyi István University, Györ, Hungary
}

Received 10 April 2021; accepted 14 August 2021

\begin{abstract}
Monetary policy uncertainty (MPU) not only imposes a great impact on the systematic financial risks of a country but also generates a significant spillover effect on countries having close economic exchanges with the former under the background of global economic integration. With the daily return rates of 64 listed financial companies in China from February 2006 to September 2020 used as the samples, China's systematic financial risks were measured in this research by using long-run marginal expected shortfall (LRMES). On this basis, an FAVAR model with time-varying parameters was constructed to empirically investigate the spillover effect of US MPU on China's systematic financial risks and its main transmission channels. Results showed that within the sample period (February 2006 - September 2020), US MPU generated a significant positive spillover effect on China's systematic financial risks, namely, China's systematic financial risks would be aggravated if the level of US MPU was elevated. From different time intervals, the spillover level was particularly high during global financial crises and global COVID-19 pandemic, indicating that the spillover effect of MPU is nonlinear and closely related to global major sudden risk events. Through the further research, it is found that this effect is mainly transmitted through short-term capital flow, interest rate, and economic uncertainty-induced channels, among which the short-term capital flow is the most important.
\end{abstract}

Keywords: MPU, spillover effect, systematic financial risks, nonlinear, LRMES, global major financial risk events.

JEL Classification: E52, F42, G21.

\section{Introduction}

As an important instrument for the government to implement macro-regulations, monetary policies not only affect national economies but also create a spillover effect on the economic activities in other countries under the background of global economic integration (Kim, 2001). The monetary policy adjustment of the Federal Reserve (Fed) in the US, the largest

${ }^{\star}$ Corresponding author. E-mail: doujiang1024@163.com

Copyright (C) 2022 The Author(s). Published by Vilnius Gediminas Technical University

This is an Open Access article distributed under the terms of the Creative Commons Attribution License (http://creativecommons. org/licenses/by/4.0/), which permits unrestricted use, distribution, and reproduction in any medium, provided the original author and source are credited. 
economy in the globe, has a self-evident spillover effect on other economies. To rejuvenate the US economy after the outburst of the Subprime Crisis, the Fed implemented four rounds of quantitative easing. With the recovery and gradual improvement of the US economy, the Fed ended its quantitative easing and restarted its interest rate increase and balance sheet shrinkage plan in 2016. As COVID-19 spread across the globe in 2020, the Fed carried out an unprecedented unlimited quantitative easing monetary policy to cope with the negative impacts of the pandemic on the economy. Therefore, the monetary policy tools of the Fed shifted between "conventional" and "unconventional", they were restricted by the effectiveness of expectations of economic subjects on new policies, thereby significantly increasing the US monetary policy uncertainty (MPU) (Husted et al., 2020). Previous studies have shown that the US MPU generates a spillover effect on the economic activities and financial markets in China and other countries through exchange rates, interest rates, trade, capital flow, and other channels (Baker et al., 2016; Ho et al., 2018; Jiang et al., 2019a). With the continuously accelerated global financial integration progress and gradual opening of transaction channels such as "Shanghai-London Stock Connect" and "Shanghai-Hong Kong Stock Connect", the cross-border financial risk shock faced by China is increasingly aggravated. Therefore, if the spillover effect of US MPU on China is neglected, then government sectors may be stuck in deviations when formulating macroeconomic policies, which may even aggravate the instability of the financial system and further lead to systematic financial risks.

Preventing and resolving major financial risks and holding out the baseline for systematic financial risks constitute a significant deployment made by the Central Committee of the Communist Party of China in the financial field in the new era and an inevitable requirement for the financial industry to serve the real economy and realize high-quality economic development. The accumulation of systematic financial risks is mainly attributed to two aspects, namely, the internal factors and external impacts of the financial system (Yang et al., 2020), and monetary policy adjustment is an important external impact that triggers systematic financial risks (Borio \& Zhu, 2012; Fang, 2015). The impacts of monetary policies on systematic financial risks include policy level and uncertainty impacts. At present, scholars have paid much attention to the monetary policy level impact and neglected the importance of the uncertainty impact of monetary policies to a certain extent. Given the ever-increasing US MPU and its significant spillover effect on economic and financial activities in other countries, the following questions worthy of exploration are proposed: Does US MPU has a spillover effect on China's systematic financial risks? If yes, then what are the main spillover channels? Furthermore, according to the recent research findings, the international spillover effect of economic policy uncertainty is nonlinear (Gabauer \& Gupta, 2018), namely, the spillover intensity of economic policy uncertainty will change with the external economic environment. Since 2006, the global economic and political pattern has been changed unpredictably. Extreme risk events take place frequently, such as the US subprime mortgage crisis, European debt crisis and global COVID-19 pandemic, leading to the violent oscillation of financial market and cross-border contagion of financial risks. Under this background, will the spillover effect of US MPU on China's systematic financial risks be of nonlinearity? Answering the above question will not only facilitate to better prevent the risk resonance triggered by the cross-border and cross-market contagion but also it is conducive to correctly 
evaluating the status of MPU in the risk transfer chain of financial markets all over the world and providing a new decision-making idea for China to establish a risk early warning system, solidify the defensive line of financial security and neutralize input risk shock.

The marginal contributions of this study are as follows. First, based on the transnational spillover characteristics of monetary policies on systematic financial risks, the nonlinear spillover effect of the Fed's MPU on China's systematic financial risks and its transmission mechanism were theoretically studied from the MPU perspective. Second, a factor-augmented vector autoregressive (FAVAR) approach with the time-varying parameters (TVP) model was constructed following the conclusions of previous theoretical research. This study is the first to empirically examine the nonlinear spillover effect of the Fed's MPU on China's systematic financial risks and its transmission channels and highlight the generating mechanism of nonlinearity. Third, the LRMES method was used to measure China's systematic financial risks, thereby providing a novel idea for measuring such risks.

The rest of this study is organized as follows. Section 1 presents a literature review and research hypotheses, summarizes the research progress regarding the spillover effect of MPU, and proposes the spillover effect of US MPU on China's systematic financial risks and its transmission channels. Section 2 presents the research methodology, including the model design, variables processing, and common factor extraction. Section 3 analyzes the empirical results, the nonlinear spillover characteristics of US monetary policies on China's systematic financial risks, and the main spillover channels. Section 4 describes the empirical findings. The last Section summarizes the conclusions and limitations.

\section{Literature review and hypothesis development}

\subsection{Literature review}

Monetary policies, as one of the most important economic means adopted by central banks to implement macro-regulations, have always been a research hotspot. Previous studies on this topic have focused on the effects of monetary policies on macroeconomic variables. For instance, Friedman et al. (1963) found that the influence of monetary policies on actual output might last two years or even longer. The importance of the transmission channel effects of monetary policies has increased along with the deepening of these studies. According to Mishkin (1995), monetary policies are transmitted mainly through two basic channels, namely, currency and credit. Following the Subprime Crisis that was triggered by the Fed's long-term implementation of loose monetary policies, scholars have started rethinking and reviewing the transmission channels of monetary policies. Under this background, the risktaking channel of monetary policies has been proposed as a novel transmission channel that is widely accepted by academic circles. Scholars have meticulously and deeply probed into the existence of the risk-taking channels of monetary policies and their transmission mechanism.

With the continued economic globalization and financial integration, the international capital flow provides the conditions necessary for the international spillover of financial risks, and follow-up research has focused on the spillover effect of monetary policies on bank risk-taking under open economic conditions. Representative studies include Bruno and Shin (2015), who empirically tested the association between cross-border capital flow and financial 
risks, and found that the loose monetary policies in developed economies facilitate crossborder capital flow, elevate the bank risk-taking level in spill-in countries. As for theoretical research, He and Li (2018) examined the risk-taking effect of China's international capital flow by constructing the DSGE model under open economic conditions and used empirical data to verify the international risk-taking channel effect. According to economic theories, the monetary policy impact covers two aspects, namely, policy-level impact and uncertainty impact. With the MPU evaluation and breakthrough of measurement technologies in recent years, the international spillover effect and spillover channels of MPU have been continuously investigated (Husted et al., 2020). Similar to monetary policies, the MPU of dominant economies also generates a spillover effect on the economic activities in other countries. Based on this idea, beneficial trials have been performed to study the transnational spillover effect of MPU in developed economies, such as Europe and the US, within academic circles. For example, Gabauer and Gupta (2018) found that the US MPU drove the uncertainty of Japanese trade policies. Recently, it has been found that the spillover effect of MPU has the nonlinear time-varying feature. For instance, Cai (2018) pointed out the nonlinear spillover effect of US MPU on return on stocks in Australia and New Zealand.

The parameter-fixed vector autoregression (VAR) model has been widely used in empirical studies to examine the international spillover effect of economic policy uncertainty (EPU). For example, Colombo (2013) explored the influence of US EPU on the macroeconomy in the Eurozone via the structural VAR model. Ho et al. (2018) investigated the spillover effect of US EPU on China's real estate market, stock market, and credit market by using the FAVAR model. However, the parameter-fixed VAR model fails to capture the differences in the spillover degree and spillover direction of EPU across different periods, that is, the nonlinear feature of the spillover effect. Many scholars have also used the VAR model with time-varying parameters (TVP-VAR) or the nonlinear smooth transition VAR (STVAR) model to study the nonlinear spillover effect of EPU on the economy of other countries. Representative studies include Caggiano et al. (2020), who tested the nonlinear spillover effect of US EPU on the unemployment rate in Canada in two different periods-booms and busts-based on the STVAR model and found that this unemployment rate bore a greater negative impact during an economic depression. Jiang et al. (2019b) used the TVP-VAR model to examine the spillover effect of Sino-US economic policy uncertainties and found that the Sino-US transnational spillover effect is mainly affected by bilateral trade, exchange rate, and investor sentiment.

The above literature review highlights a certain room for expansion. First, the spillover effect of US MPU on China has only been investigated in few studies, and these studies have mainly focused on macroeconomy or EPU while ignoring the spillover effect of US MPU on China's systematic financial risks. Second, although both TVP-VAR and STVAR models can be used to examine the nonlinear spillover effect of MPU, they are small-scale VAR models with various deficiencies, such as their limited number of variables and omission of important economic information, which can easily lead to estimate bias. To address these deficiencies, the nonlinear spillover effect of US MPU on China's systematic financial risks will be empirically tested along with the main spillover channels via a theoretical analysis. 


\subsection{Hypothesis development}

The causes of systematic financial risks can be largely divided into internal factors and external impacts (Fang, 2015). Relative to other types of financial risks, the formation of systematic financial risks is mostly ascribed to external impacts, which hereinafter refer to risk sources. As an important external negative impact disturbing normal economic operations (Bloom, 2014), EPU can easily result in the contagion and sheep-flock effect of investors' panic, lead to a bank run and trigger systematic financial risks. The influence of EPU on systematic financial risks is mainly manifested in two aspects. First, the EPU affects the active risk-taking level of banks (Hao et al., 2017). On the one hand, according to the theory of real option, the elevation of EPU increases the value for enterprises to wait for investment opportunities, thereby arousing the expectations of the enterprise management level and enhance its willingness to wait, thereby restricting enterprise investment activities (Dixit et al., 1999; Ouyang et al., 2018) and eventually reducing the credit needs of the banking sector. On the other hand, the theory of precautionary saving posits that the enterprise management level may shrink its investment scale and increase its savings to cope with the liquidity plight brought about by EPU (Zhang \& Liu, 2018). Under the influence of these double factors, the net liquidity position held by the banking sector will increase, and in response to the professional managers' pursuit of profits and the competitive pressure within the industry, banks will ease their credit approval conditions to increase their credit scale, risk tolerance, and risk-taking level.

In addition, the EPU will influence banks' passive risk-taking levels ( $\mathrm{Gu} \& \mathrm{Yu}, 2019$ ) for three reasons. First, the EPU generates a negative impact on macroeconomic activities, degrades the profitability and debt-paying ability of the industry and enterprises (Yang et al., 2020), and increases the risk of bankruptcy and default rate. Second, the EPU will negatively impact the stock market, and the values of mortgages with which enterprises apply for loans from banks using pledging stock rights will decrease (Pastor \& Veronesi, 2012), thereby increasing the credit default risk faced by these banks. Third, the EPU will aggravate the information asymmetry between enterprises and the banking sector, hence hindering banks from accurately evaluating the debt-paying ability and credit risk of enterprises (Gu \& Yu, 2018). As a result, bank managers will commit mistakes when making decisions related to credit loan placement, consequently increasing banks' passive risktaking level because when the EPU is partially high, the features of borrowers will become non-transparent, which may trigger biased errors during the identification of enterprise credit risks. Moreover, loans will be given to enterprises with relatively poor loan repayment ability (Chi \& Li, 2017; Phan et al., 2021). The MPU not only belongs to the category of EPU but is also an important constituent of EPU. Based on the above analysis, the MPU will aggravate systematic financial risks. The US is not only a developed economy but also a country that dominates the global economy. Therefore, the Fed's MPU will affect the systematic financial risks in the US and generate a spillover effect on those countries that keep close economic and financial trade contacts with the former under open economic conditions (Jiang et al., 2019b). Given that China is the second-largest economy in the world and the main economic and trade partner of the US, the US MPU will also generate a spillover effect on China's systematic financial risks. 
Based on the above analysis, the following Hypothesis 1 is proposed: US MPU generates a spillover effect on China's systematic financial risks.

US MPU generates a spillover effect on China's systematic financial risks mainly through three channels. The first channel is short-term capital flow, and its mechanism is described as follows. With an increasing US MPU, short-term capital will flow out of the US into the China's market (Hau \& Rey, 2008; Fratzscher \& Straub, 2013), thereby aggravating China's systematic financial risks. Specifically, the elevation of MPU as induced by the Fed's frequent adjustment of its monetary policies will generate negative impacts on the economic activities in the US and weaken investors' confidence in the US market. China's economic market presents a "haven" for transnational investment by virtue of its good investment environment and investment opportunities, strong economic resilience, and broad prospects. Therefore, international short-term capitals will flow into the Chinese market. According to the theory of third-generation money, the large-scale inflow of short-term capital will aggravate the fragility of the domestic financial system and easily trigger systematic financial risks (Kaminsky \& Reinhart, 1998). The second channel is the EPU-induced channel, whose mechanism is explained as follows. Given that the US is a dominant economy, a change in the Fed's monetary policy stance will change the monetary policy trends of central banks around the globe, that is, the US MPU will trigger the Chinese government to make the corresponding adjustments to its economic policies, such as monetary and fiscal policies, and eventually increase China's EPU. Following this discussion, the systematic financial risks will be aggravated due to the elevation of China's EPU. The third channel is the interest rate, whose mechanism is described as follows. In the US, the Fed manipulates the general valve of global liquidity. When the US MPU increases, the global economy becomes faced with a major risk event (Colombo, 2013). To cope with this global risk and stabilize its domestic economy, the Central Bank of China down-regulates its interest rates, and the resulting low-interest-rate environment will elevate the risk-taking level of banks and easily trigger systematic financial risks (Borio \& Zhu, 2012; Adrian \& Shin, 2009; Angeloni et al., 2015).

Following the above discussion, the following Hypothesis 2 is proposed: US MPU generates a spillover effect on China's systematic financial risks mainly through the short-term capital flow, interest rate, and EPU-induced channels.

The transnational spillover degree of MPU is not only closely related to the economic development level, opening degree of the capital market, exchange rate, and bilateral trade policies of the spill-in country but also to global major sudden risk events (Clayes, 2017), the transnational spillover effect of MPU may be nonlinear. After the occurrence of a global major risk event, the Fed actively adjusts its monetary policies to cope with the negative impacts of such events on the US economy, thereby increasing its MPU to a great extent. For instance, according to the EPU indexes of global main economies as estimated by Baker et al. (2016), the US MPU index reached as high as 304.07 in March 2020 as the COVID-19 pandemic rapidly spread across the US and the globe, thereby marking a new high since the 911 terrorist attack event. When such uncertainty increases further, the signal of economic operation uncertainty can be easily transmitted to other economies and the spillover effect on other countries will be strengthened (Zhang \& Chen, 2019). Furthermore, the US economy will be significantly negatively affected by any global major sudden risk event and may even 
be stuck in an economic recession, which will surely generate an intense spillover effect on countries that maintain close economic and trade relations with this country (Li et al., 2021). Therefore, influenced by global major risk events, the US MPU generates a highly significant transnational spillover effect on China's systematic financial risks.

According to the above analysis, the following Hypothesis 3 is proposed: Affected by global major sudden risk events, the spillover effect of the US MPU on the systematic risks in China is nonlinear.

\section{Methodology}

\subsection{Modeling}

VAR models are classical empirical approaches used to investigate the transnational spillover effect of EPU. In relevant domestic and foreign literature, VAR models of threshold mechanism transfer, Markov state transition, and time-varying parameters have been used to depict the nonlinear feature of EPU spillover effects (Caggiano et al., 2020; Antonakakis et al., 2019), and these three nonlinear models have their respective advantages and disadvantages. Both VAR models of threshold mechanism transfer and Markov state transition describe nonlinear features through the mechanical transfer of single or several variables, and the quantity of nonlinear structural breakpoints they capture is extremely limited (Ouyang et al., 2018). According to the above theory, the transnational spillover effect of MPU results from the joint action of the economic development level of a spill-in country, the opening degree of the capital market, exchange rate, and bilateral trade policies, and global major sudden public events. Obviously, the ways through which these models depict nonlinearity do not apply to this study. The VAR model of time-varying parameters can conveniently describe the complex nonlinearity with a nonintuitive economic meaning between economic variables, which is its apparent advantage. Given the defects of the existing TVP-VAR models, Korobilis (2013) introduced the idea of dynamic factor extension into the TVP-VAR model and proposed the TVP-FAVAR model, which not only depicts the time-varying nonlinear feature between variables but also effectively reduces estimate bias due to the omission of important economic variables. The model settings are as follows:

$$
\begin{gathered}
X_{t}=\lambda_{t}^{y} Y_{t}+\lambda_{t}^{f} F_{t}+u_{t}, \quad u_{t} \sim N\left(0, V_{t}\right) \\
{\left[\begin{array}{c}
F_{t} \\
Y_{t}
\end{array}\right]=B_{t, 1}\left[\begin{array}{c}
F_{t-1} \\
Y_{t-1}
\end{array}\right]+\cdots+B_{t, p}\left[\begin{array}{c}
F_{t-p} \\
Y_{t-p}
\end{array}\right]+\varepsilon_{t}, \quad \varepsilon_{t} \sim N\left(0, Q_{t}\right),}
\end{gathered}
$$

where $X_{t}$ is an $n \times 1-$ dimensional steady vector that includes the domestic and internal factors of systematic financial risks as well as the three spillover channels of China's systematic financial risks, $F_{t}$ is a $l$-dimensional unobservable common factor, $Y_{t}$ is the US MPU index that can be construed as an observable factor, $\lambda_{t}^{y}$ and $\lambda_{t}^{f}$ denote the time-varying loading matrix of the common factor, $B t, p$ is a lagged term coefficient, $p$ is a lag order, $\varepsilon_{t}$ and $u_{t}$ is a residual error term that represents common and peculiar impacts. In addition, 
the subscript $t$ indicates that the coefficient is time-varying and depicts the nonlinearity of the spillover effect of US MPU on China's systematic financial risks. Model (2) is re-expressed as follows by using matrix language:

where $G_{t}=\left(Y_{t}^{\prime}, F_{t}^{\prime}\right)^{\prime}, \beta_{t}=\left(\operatorname{vec}\left(B_{t, 1}\right)^{\prime}, \operatorname{vec}\left(B_{t, 2}\right)^{\prime}, \cdots, \operatorname{vec}\left(B_{t, j}\right)^{\prime}\right)^{\prime} . \lambda_{t}=\left(\left(\lambda_{t}^{y}\right)^{\prime},\left(\lambda_{t}^{f}\right)^{\prime}\right)^{\prime}$ is set, and firstorder random walk is used to depict the lagged term coefficient and time-varying feature of factor loading as follows:

$$
\begin{array}{ll}
\beta_{t}=\beta_{t-1}+\eta_{t}, & \eta_{t} \sim N\left(0, R_{t}\right) ; \\
\lambda_{t}=\lambda_{t-1}+v_{t}, & v_{t} \sim N\left(0, W_{t}\right) .
\end{array}
$$

The time-varying feature of the peculiar disturbing term $V_{t}$ and common disturbing term $Q_{t}$ is generally depicted by using the stochastic volatility (SV) model or the generalized autoregression condition heteroscedasticity (GARCH) model. However, according to Korobilis (2013), this setting will increase the calculation burden in estimating the model parameters. Accordingly, he used the simulation-free matrix discounting method (also known as exponential weighting moving average or EMWA) to depict the time-varying features of $V_{t}$ and $Q_{t}$ as follows:

$$
\begin{aligned}
& V_{t}=k_{1} V_{t-1}+\left(1-k_{1}\right) u_{t} u_{t}^{\prime} ; \\
& Q_{t}=k_{2} Q_{t-1}+\left(1-k_{2}\right) \varepsilon_{t} \varepsilon_{t}^{\prime},
\end{aligned}
$$

where $k_{1}$ and $k_{2}$ are the decay factors that are used to depict the attenuation amplitude of disturbing impact with time.

\subsection{Variable explanation and processing and common factor extraction}

\section{(1) Variable explanation}

According to the above TVP-FAVAR model settings, the main model variables include US MPU, international and domestic macroeconomic datasets, China's systematic financial risk, and spillover channels.

The US policy uncertainty index developed by Baker et al. (2016) based on newspaper coverage frequency is denoted by MPU. The index is calculated according to the proportion of keywords "monetary policy" and "uncertainty" appearing in the reports of 10 main US newspapers in the current month. Given that the MPU index measured through this method can capture how the expectations of microeconomic subjects affect the changes in the Fed's monetary policy trend and economic consequences; this approach has been extensively applied in MPU-related studies (Ho et al., 2018).

Given the certain divergence over the formation causes and recognition of systematic financial risks within academic circles, the methods used for measuring systematic financial risks are varied and distinctive. The measured systematic financial risks obtained by virtue of the accessibility, high frequency, and strong forward-looking property of capital market data are relatively objective and have been widely used as references in domestic and foreign studies. Therefore, the LRMES method proposed by Brownlees and Engle (2017) was used to measure China's systematic financial risks. Following the industry classification standard 
of China Securities Regulatory Commission, 64 A-share listed financial companies were selected between February 6, 2006 and September 30, 2020 (including 3,571 trading days) in consideration of the strong financial nature of China's real estate industry. Given that the total market value of the sampled companies accounted for approximately $82.5 \%$ of the total market value of the financial and real estate industries, they could represent the overall situation of China's financial system. Combining the needs of this study, the daily frequency LRMES was converted into monthly LRMES based on their arithmetic mean value, and the measurement results are presented in Figure 1.

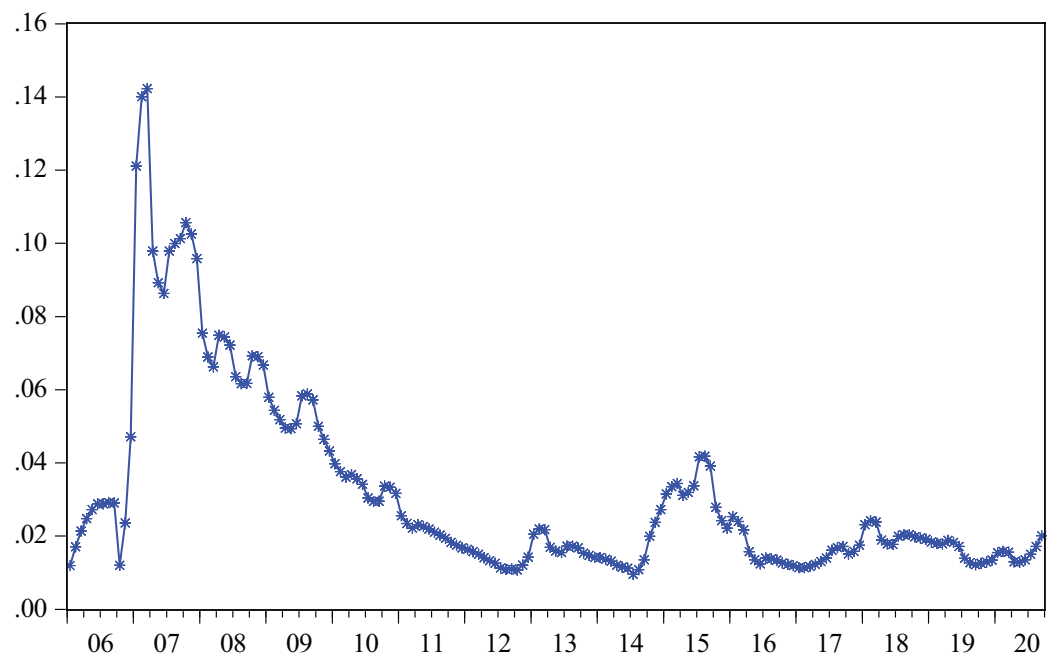

Figure 1. China's Systematic Financial Risks (2006M02-2020M09)

As shown in Figure 1, China's systematic financial risks were located at staged high positions during the global financial crisis (2007-2008), European debt crisis (2009), and stock market crash (2015). These risks were especially obvious during the global financial crisis, which accounted for the long duration and great destruction of this round of financial crisis. To cope with the negative impacts of the global financial crisis on China's real economy, the Chinese government formulated an "RMB 4,000 billion" fiscal incentive plan and a moderately loose monetary policy to control and quiet down the overall risk. Afterward, the overall risk climbed by a small margin under the impacts of negative events, such as the historic "money shortage" of China's banking industry (2013M06), the Sino-US trade war (2018M03), and COVID-19. In sum, the LRMES measurement results agree well with the dynamic trend in China's systematic financial risks.

The international macroeconomic information set includes: (1) the economic growth rates of China's principal trade partners, including the GDP growth rates of the US, Japan, Eurozone, and South Korea; (2) money supplies of main developed economies, including the M2 year-on-year growth rate of the US and Japan and the M3 year-on-year growth rate of South Korea and Eurozone; (3) the main US macroeconomic indexes, including CPI, yearon-year growth rate of imports and exports, and PMI of the manufacturing and non-manufacturing industries; and (4) exchange rate, including USD/CNY and EUR/CNY exchange 
rates and $\mathrm{CNY}$ effective exchange rate index. Meanwhile, the domestic macroeconomic information set includes: (1) actual output, including industrial added value, yield of main energy products (e.g., raw coal, coke, and electric energy production), and yield of important industrial products (e.g., pig iron, crude steel, and cement); (2) actual investment, including completed amounts of fixed asset investments, real estate development investments, and fixed asset investments of the tertiary industry; (3) capital market price, including the Shanghai and Shenzhen 300 indices, total market value, circulation market value, and average price-toearnings ratio of domestic listed companies; (4) macroeconomic climate index, including the coincidence, leading, and lagging indices; (5) trade, including total export-import volume and net gross exports of China; (6) China's monetary policies, including its M2 year-on-year growth rate, demand deposit interest rate, and fixed-term deposit rate; and (7) other data, including 94-dimensional data such as CPI, PPI, balance of loans and deposits of financial institutions, and fiscal revenue.

The short-term capital flow channel (CF) was calculated following the indirect measurement method proposed by Peng and Zhu (2019) as follows: short-term capital flow = accrual of foreign exchange reserve - amount of trade surplus - foreign direct investment. Meanwhile, for the interest rate channel, following the basic completion of China's interest rate marketization, interbank offer rate gradually became the "wind indicator" of monetary policies given its ability to timely and accurately reflects the changes in market interest rate. Based on this indicator, the method of $\mathrm{Li}$ and Tian (2020) was taken as reference, and the seven-day interbank offer rate was chosen as the proxy for interest rate channel and denoted by IRL. In terms of China's EPU-induced channel, China's EPU index as measured by Baker et al. (2016) based on big text data was used and denoted by $\mathrm{CH}_{-} E P U$.

\section{(2) Variable processing}

All data used in this study were monthly with a time interval of 2006M2-2020M09, which covered global major sudden risk events, such as the global financial crisis, the European debt crisis, and the COVID-19 pandemic. Therefore, the nonlinear feature of the spillover effect of US MPU on China's systematic financial risks could be well depicted. The high-dimensional international and domestic macroeconomic information sets and spillover channel data were all taken from the Wind database, and the US MPU and China EPU indexes were obtained from http://www.policyuncertainty.com.

By taking into consideration the needs of this research, the original data were processed as follows: (1) those variables measured in USD, such as imports and exports, were converted into CNY; (2) those sequences containing seasonal components, such as imports and exports, were deseasonalized by using the Census_12 method; (3) the nominal aggregate data, such as GDP and fixed asset investments, were initially converted into actual data by using CPI with a 2005 base period, the logarithm was taken, and the data were transformed into year-on-year data via differential conversion; and (4) all data were standardized, and a differential processing was performed for those sequences not satisfying $I(0)$, such as fixed asset investments. 


\section{Results analysis}

\subsection{Spillover effect of US MPU on China's systematic financial risks}

According to the pulse response results in Figure 2, one unit of US_MPU positive impact was given, and the pulse response value of LRMES in the current period was mainly positive, thereby indicating that US MPU had a significant positive spillover effect on China's systematic financial risks, that is, the elevation of US MPU would aggravate China's systematic financial risks in the short term. Across different intervals, including the global financial crisis (2007-2009) and the European debt crisis (2011-2015), US MPU had a great influence on China's systematic financial risks with a maximum positive response value of 0.02 . However, the duration of the spillover effect was relatively short and disappeared in the 8th month. Given that the Fed entered the interest-rate hike cycle (2016-2017), US MPU had a relatively low degree of influence on China's systematic financial risks with a maximum positive response value of 0.01. During the COVID-19 pandemic (2020), the US MPU resulted in the largest fluctuation amplitude of China's systematic financial risks. The maximum positive response value was 0.052 within a long duration and did not disappear until the 18 th month.

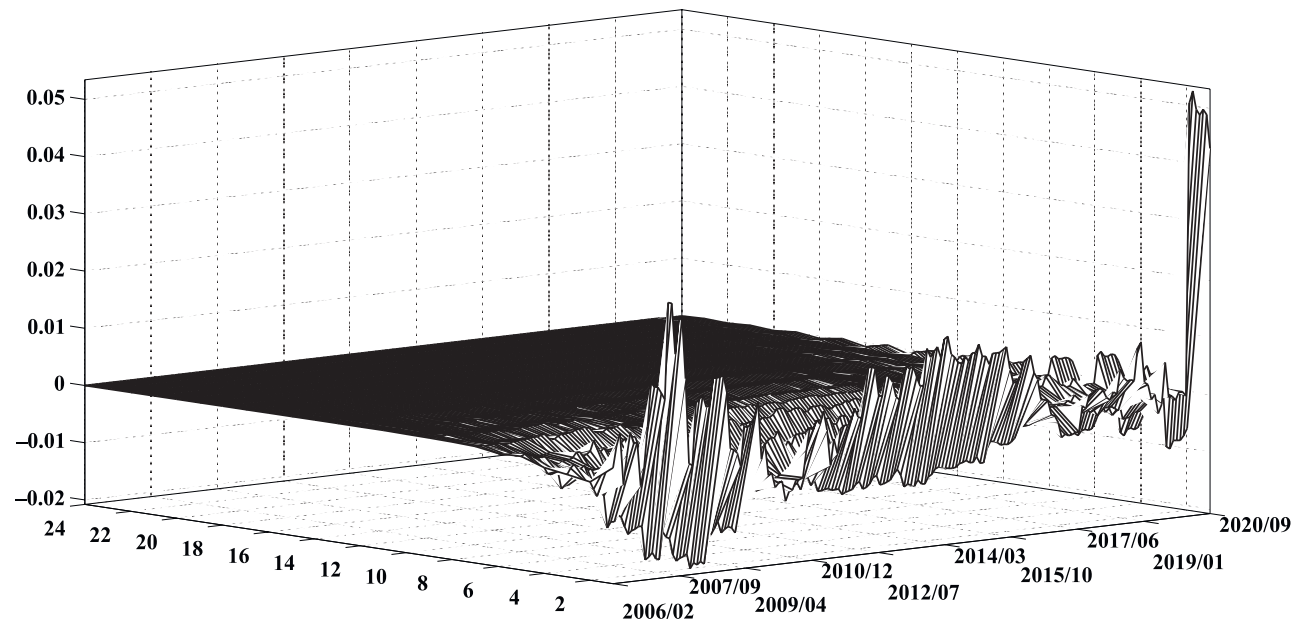

Figure 2. US_MPU $\rightarrow$ LRMES

\subsection{Spillover channel of US MPU on China's systematic financial risks}

According to the pulse response results in Figure 3, one unit of US_MPU positive impact was given, whereas the pulse response value of CF in the current period was mainly positive, thereby suggesting that capital would flow into the Chinese market within a short period under an elevated US MPU. Across different intervals, such as the global financial crisis (2007-2009) and the European debt crisis (2011-2015), the short-term capital flow was affected by US MPU to a great extent, and the maximum positive response value was 0.15 . However, the duration of the spillover effect was relatively short and disappeared in the 10th month. After the Fed entered the interest-rate hike cycle (2016-2017), the US MPU exerted a relatively weak influence on China's systematic financial risks, and the maximum positive response value was 0.01 . 
During the COVID-19 pandemic, the fluctuation amplitude of short-term capital flow reached its peak due to US MPU impact, the maximum positive response value was 0.045 , the duration was the longest, and this value did not disappear until the 20th month.

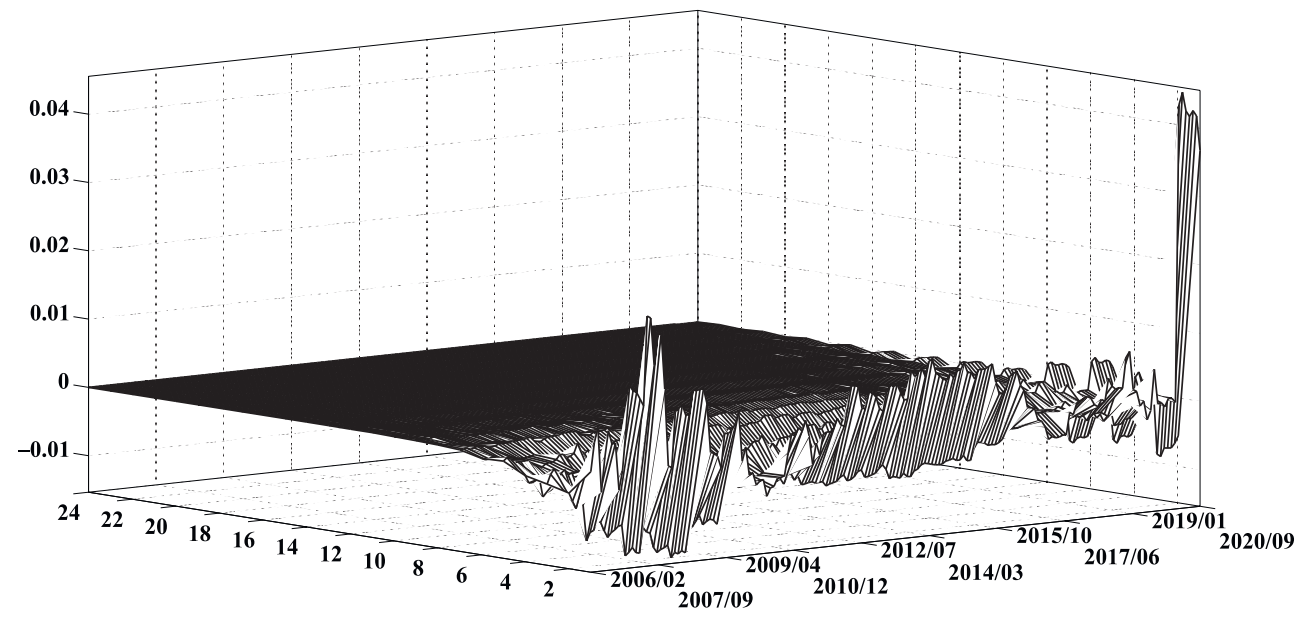

Figure 3. US_MPU $\rightarrow \rightarrow C F$

According to the pulse response results in Figure 4, one unit of US_MPU positive impact was given, whereas the pulse response value of IRL in the current period was mainly negative, thereby indicating that the interest rate in the Chinese market would drop due to the elevated US MPU. Across different intervals, the short-term capital flow was affected by the US MPU impact to a great extent, the minimum response value was -0.028 , the duration of the spillover effect was relatively short, and such effect disappeared in the 6th month. During the COVID-19 pandemic, the fluctuation amplitude of short-term capital flow was the largest due to the US MPU impact, the reduction degree of interest rate in the Chinese market reached its peak due to the US MPU impact, the minimum response value was -0.069 , the duration was the longest, and the effect did not disappear until the 22th month.

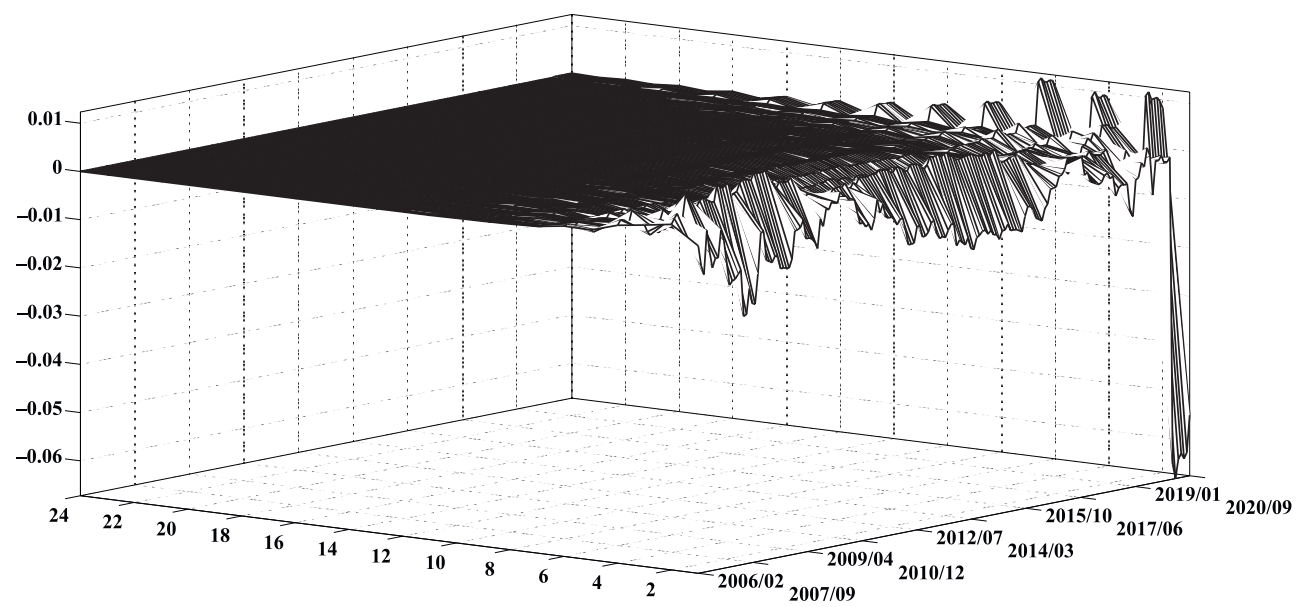

Figure 4. US_MPU $\rightarrow I R L$ 
According to the pulse response results in Figure 5, one unit of US_MPU positive impact was given, the pulse response value of $\mathrm{CH}_{-} E P U$ in the current period was mainly positive, thereby indicating that China's EPU will be aggravated under an elevated US MPU. Across different intervals, the US MPU greatly affected China's policy uncertainty, the maximum positive response value was -0.002 , the duration of the spillover effect was relatively short, and such effect disappeared in the 8th month. During the COVID-19 pandemic, the increase amplitude of China's policy uncertainty reached its peak due to the US MPU impact, the maximum positive response value was 0.016 , the duration was the longest, and the effect did not disappear until the 16th month.

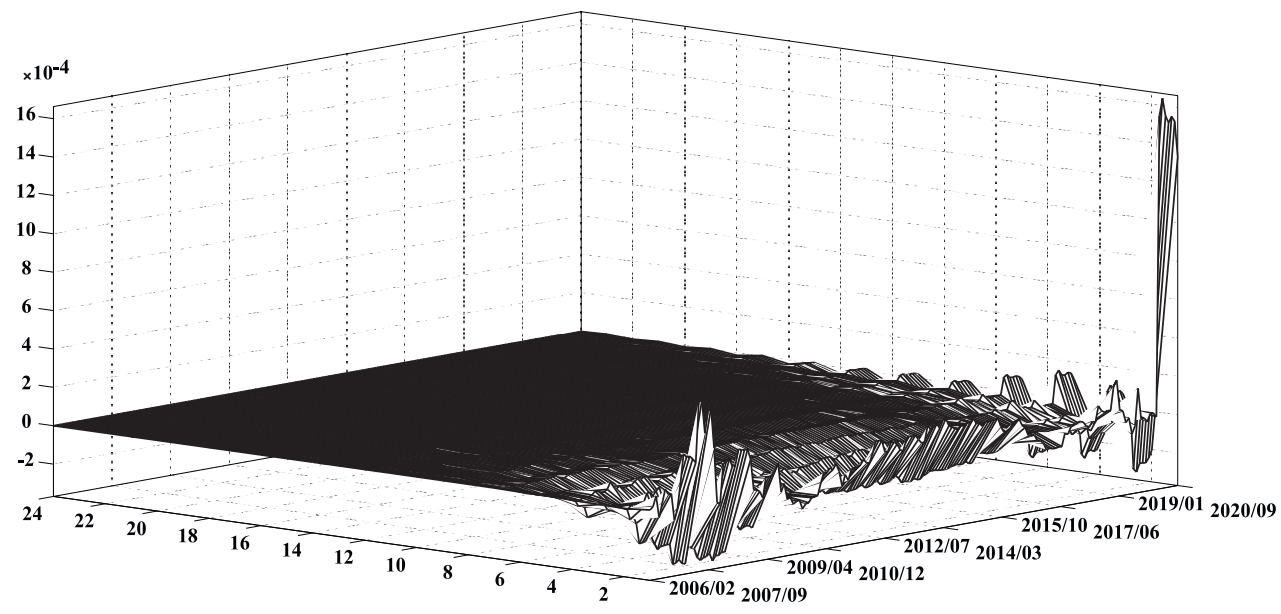

Figure 5. US_MPU $\uparrow \rightarrow \mathrm{CH}_{-} E P U$

\section{Discussion}

The above empirical results suggest that the US MPU generates a spillover effect on China's systematic financial risks via short-term capital flow, interest rate, and EPU-induced channel, and the spillover degree is closely related to global major risk events, thereby suggesting that this spillover is nonlinear.

As shown in Figure 2, the elevated US MPU generates a significant spillover effect on China's systematic financial risks because during the global integration process, China is opening its national capital market step by step. Under this background, the financial market-overseas market co-movement is enhanced, and the transnational risk contagion of US MPU is aggravated (Yang et al., 2020). Across different intervals, the spillover effect generated by the US MPU was especially obvious during the global financial crisis and the COVID-19 pandemic, which means that the abovementioned spillover effect is closely associated with global major risk events and is nonlinear. First, global major risk events are abrupt and uncertain, and the Fed will timely adjust its monetary policies to mitigate the negative impacts of these events on the US economy, which will consequently increase US MPU; a higher degree of uncertainty corresponds to a greater spillover level (Clayes, 2017). Second, these global major risk events are contagious and will not only affect the systematic 
financial risks in the country but also generate a significant spillover effect on close-contact countries (Yang et al., 2020).

Figure 3 shows that US MPU generates a significant positive spillover effect on short-term capital flow, that is, an elevated level of US MPU aggravates the capital flow into the Chinese market, which is consistent with the conclusions of Fratzscher and Straub (2013). Under an elevated level of US MPU, US investors may show aversion to risks, thereby accelerating capital outflow (Hau \& Rey, 2008). Relatively speaking, China is the first choice for investors to evade risks by virtue of its resilient economic growth and favorable long-term trend of fundamentals, and in the end, the short-term capital inflow scale will expand.

As shown in Figure 4, the US MPU has a remarkable negative spillover effect on the interest in the Chinese market, that is, the interest rate will decline under an elevated level of US MPU. While manipulating the "general valve" of global liquidity, the Fed will implement the quantitative easing monetary policy of "benefiting itself at others' expense" to cope with the negative impacts of global major risk events. Given the obvious arbitrage space, hot money flows from the US to China and the interbank offer rate declines by a large margin (Jin \& Zhang, 2017). This argument contradicts the results of Jiang (2020), who found that the US EPU increases the loan interest rate in emerging economies, and such inconsistency may be ascribed to the fact that the work of Jiang (2020) was based on a linear measurement model.

Figure 5 shows that the US MPU generates a significant positive spillover effect on China's EPU, that is, China's EPU will be aggravated by an increase in US MPU, which is consistent with the findings of Zhang and Chen (2019). Under the aggravated MPU of the Fed, China's monetary, fiscal, and other economic policies will change to some extent, thereby increasing China's EPU (Li et al., 2021). The increase of China's economic policy uncertainty will aggravate China's systematic financial risks, indicating the existence of economic policy uncertainty-induced channel.

A comparison of Figures 3 to 5 reveals that the spillover degree of MPU is sensitive to sudden major events, and the total spillover level climbs to its peak during the global financial crisis, the European debt crisis, and the COVID-19 pandemic. A comparison of the three transmission channels reveals that the short-term capital flow is the main spillover channel of US MPU, followed by the interest rate channel and the EPU-induced channel, which agrees with the findings of Ho et al. (2018) that trade channels played an insignificant role in the effect of U.S. monetary shocks on Chinese housing, equity, and loan markets during normal times and the zero lower bound. Our results suggest that so-called "short-term capital flow" may play an important role in the transmission mechanism.

\section{Conclusions}

The US MPU not only has a significant regulatory effect on systematic financial risks in the US but also generates an apparent spillover effect on China and other countries under the background of global economic integration. In the context of a significantly elevated US MPU in recent years, the international capital flow risk-taking effect of monetary policies was considered to study the nonlinear spillover effect of US MPU on China's systematic risks and its transmission mechanism. Based on the conclusions of theoretical research, the 
TVP-FAVAR model was constructed to empirically investigate the nonlinear spillover effect of US MPU on China's systematic financial risks. The conclusions are summarized as follows:

(1) The theoretical study in this paper shows that the increase of economic policy uncertainty will not only result in the increase of active risk-taking level and passive risk-taking level of banks in a country, so as to aggravate its systematic financial risks, but also, under the background of economic globalization, generate an influence on systematic financial risks in the countries having close relations with this country. Moreover, this influence is positive and nonlinear, and the spillover channels include short-term capital flow, interest rate channel and economic policy uncertainty-induced channel. The nonlinear feature is manifested by the nonlinear transformation of spillover effect with global major risk events. (2) The empirical study based on the TVP-FAVAR model indicates that Fed MPU exerts a significantly positive spillover effect on China's systematic financial risks, and the spillover level is closely associated with global major financial risk events. To be specific, as the spillover effect of MPU is relatively sensitive to global major risk events and the spillover level is the highest during the global financial crisis and global COVID-19 pandemic, manifesting that the major sudden events bursting out in a country or a region aggravate the level of global economic policy uncertainty, and the economic policy uncertainty is positively correlated with the spillover effect. (3) It is also found through the empirical study that during the sample period, US MPU generates the nonlinear spillover effect on China's systematic financial risks respectively through short-term capital flow, interest rate channel and economic policy uncertainty-induced channel, where the short-term capital flow is the most important. This reflects that in comparison to domestic investment, short-term capital is more sensitive to the fluctuations in policy. When the economic policy uncertainty in a country is increased, enterprises will reduce their investments in this country, thus flowing to the economic entities with relatively stable policies.

These conclusions bring significant theoretical and practical significance for relieving the current spillover effect of US MPU on China's systematic financial risks and for preventing and resolving the related risks. However, some limitations need to be considered. For example, apart from being affected by global major sudden risk events, the nonlinear spillover effect generated by MPU is also closely related to the capital opening and economic development degrees in the recipient country, which can be comprehensively considered in follow-up research.

\section{Funding}

This work was supported by the Outstanding Youth Project of the Education Bureau of Hunan Province, China [grant number 20B326] the Construct Program of the Applied Characteristic Discipline: Applied Economics in Hunan Province[grant number 2018469]; the General Project of Hunan Social Science Achievement Evaluation Committee [grant number XSP21YBC193]; the National Natural Science Foundation of China [grant number 71973044]; Academic and Technological Leaders Project of Major disciplines in Jiangxi Province[grant number 20182BCB22008] and Medium and Long Term Research Project of Zhongnan University of Economics and Law [grant number 31510000049]. 


\section{Author contributions}

Zhenjiang Dou carried out empirical analysis and wrote the draft of the paper. Wei Lei collected data and designed the model. Zhigang Ouyang was responsible for supervising the analysis and editing the work. Vasa László analyzed the data.

\section{Disclosure statement}

Authors do not have any competing financial, professional, or personal conflict of interests from other parties.

\section{References}

Adrian, T., \& Shin, H. S. (2009). Money, liquidity, and monetary policy. American Economic Review, 99(2), 600-605. https://doi.org/10.1257/aer.99.2.600

Angeloni, I., Faia, E., \& Duca, M. L. (2015). Monetary policy and risk taking. Journal of Economic Dynamics and Control, 52, 285-307. https://doi.org/10.1016/j.jedc.2014.12.001

Antonakakis, N., Chatziantoniou, I., \& Gabauer, D. (2019). Cryptocurrency market contagion: Market uncertainty, market complexity, and dynamic portfolios. Journal of International Financial Markets, Institutions and Money, 61, 37-51. https://doi.org/10.1016/j.intfin.2019.02.003

Baker, S. R., Bloom, N., \& Davis, S. J. (2016). Measuring economic policy uncertainty. The Quarterly Journal of Economics, 131(4), 1593-1636. https://doi.org/10.1093/qje/qjw024

Bloom, N. (2014). Fluctuations in uncertainty. Journal of Economic Perspectives, 28(2), 153-176. https://doi.org/10.1257/jep.28.2.153

Borio, C., \& Zhu, H. (2012). Capital regulation, risk-taking and monetary policy: A missing link in the transmission mechanism? Journal of Financial Stability, 8(4), 236-251. https://doi.org/10.1016/j.jfs.2011.12.003

Brownlees, C., \& Engle, R. F. (2017). SRISK: A conditional capital shortfall measure of systemic risk. The Review of Financial Studies, 30(1), 48-79. https://doi.org/10.1093/rfs/hhw060

Bruno, V., \& Shin, H. S. (2015). Capital flows and the risk-taking channel of monetary policy. Journal of Monetary Economics, 71, 119-132. https://doi.org/10.1016/j.jmoneco.2014.11.011

Caggiano, G., Castelnuovo, E., \& Figueres, J. M. (2020). Economic policy uncertainty spillovers in booms and busts. Oxford Bulletin of Economics and Statistics, 82(1), 125-155. https://doi.org/10.1111/obes.12323

Cai, Y. (2018). Predictive power of US monetary policy uncertainty shock on stock returns in Australia and New Zealand. Australian Economic Papers, 57(4), 470-488. https://doi.org/10.1111/1467-8454.12130

Chi, Q., \& Li, W. (2017). Economic policy uncertainty, credit risks and banks' lending decisions: Evidence from Chinese commercial banks. China Journal of Accounting Research, 10(1), 33-50. https://doi.org/10.1016/j.cjar.2016.12.001

Claeys, P. (2017). Uncertainty spillover and policy reactions. Ensayos sobre Política Económica, 35(82), 64-77. https://doi.org/10.1016/j.espe.2017.01.003

Colombo, V. (2013). Economic policy uncertainty in the US: Does it matter for the Euro area? Economics Letters, 121(1), 39-42. https://doi.org/10.1016/j.econlet.2013.06.024

Dixit, A., Pindyck, R. S., \& Sødal, S. (1999). A markup interpretation of optimal investment rules. The Economic Journal, 109(455), 179-189. https://doi.org/10.1111/1468-0297.00426 
Fang, Y. (2015). Analysis of bank risk-taking under the impact of monetary policy and real estate prices. The Journal of World Economy, (07), 73-98.

Fratzscher, M., \& Straub, R. (2013). Asset prices, news shocks, and the trade balance. Journal of Money, Credit and Banking, 45(7), 1211-1251. https://doi.org/10.1111/jmcb.12050

Friedman, H. H., Whitney, J. E., \& Szczesniak, A. S. (1963). The texturometer: A new instrument for objective texture measurement. Journal of Food Science, 28(4), 390-396. https://doi.org/10.1111/j.1365-2621.1963.tb00216.x

Gabauer, D., \& Gupta, R. (2018). On the transmission mechanism of country-specific and international economic uncertainty spillovers: Evidence from a TVP-VAR connectedness decomposition approach. Economics Letters, 171, 63-71. https://doi.org/10.1016/j.econlet.2018.07.007

Gu, H. F., \& Yu, J. J. (2019). China's economic policy uncertainty and bank's risk-taking. The Journal of World Economy, 42(11), 148-171.

Hao, W. Y., Wei, W., \& Zhou, X. B. (2017). Research on the impact of economic policy uncertainty on bank risk-taking. Inquiry into Economic Issues, (2), 151-159.

Hau, H., \& Rey, H. (2008). Home bias at the fund level. American Economic Review, 98(2), 333-338. https://doi.org/10.1257/aer.98.2.333

He, G. H., \& Li, J. (2018). International risk-taking channel of capital flow. Economic Research Journal, 53(5), 146-160.

Ho, S. W., Zhang, J., \& Zhou, H. (2018). Hot money and quantitative easing: The spillover effects of US Monetary policy on the Chinese Economy. Journal of Money, Credit and Banking, 50(7), 1543-1569. https://doi.org/10.1111/jmcb.12501

Husted, L., Rogers, J., \& Sun, B. (2020). Monetary policy uncertainty. Journal of Monetary Economics, 115(11), 20-36. https://doi.org/10.1016/j.jmoneco.2019.07.009

Jiang, F. W., Guo, P., \& Guo, Y. M. (2019a). The impacts of Federal Reserve's monetary policy on Chinese asset prices. Journal of Financial Research, 467(5), 37-55.

Jiang, T. (2020). Spillover effect of US economic policy uncertainty: Evidence from syndicated loan in emerging economies. Finance and Trade Research, 31(2), 18-29.

Jiang, Y., Zhu, Z., Tian, G., \& Nie, H. (2019b). Determinants of within and cross-country economic policy uncertainty spillovers: Evidence from US and China. Finance Research Letters, 31, 195-206. https://doi.org/10.1016/j.frl.2019.08.004

Jin, C. Y., \& Zhang, L. (2017). The shocks of Federal Reserve's monetary policy on China's economy. China Industrial Economics, (1), 25-42.

Kaminsky, G. L., \& Reinhart, C. M. (1998). Financial crises in Asia and Latin America: Then and now. The American Economic Review, 88(2), 444-448.

Kim, S. (2001). International transmission of US monetary policy shocks: Evidence from VAR's. Journal of Monetary Economics, 48(2), 339-372. https://doi.org/10.1016/S0304-3932(01)00080-0

Korobilis, D. (2013). Assessing the transmission of monetary policy using time-varying parameter dynamic factor models. Oxford Bulletin of Economics and Statistics, 75(2), 157-179. https://doi.org/10.1111/j.1468-0084.2011.00687.x

Li, S. J., \& Tian, G. Q. (2020). Bank competition and the bank risk-taking channel of monetary policy: Theoretical and empirical research. Management World, 36(4), 149-168.

Li, Z., Zhu, M. H., \& Wen, B. H. (2021). The cross-country spillover effect of economic policy uncertainty and the working mechanism. Finance \& Trade Economics, 42(1), 92-106.

Mishkin, F. S. (1995). Symposium on the monetary transmission mechanism. Journal of Economic Perspectives, 9(4), 3-10. https://doi.org/10.1257/jep.9.4.3

Ouyang, Z. G., He, F. M., \& Xue, L. (2018). Economic policy uncertainty, dual-wheel drive and economic growth. Systems Engineering - Theory \& Practice, 39(4), 986-1000. 
Pastor, L., \& Veronesi, P. (2012). Uncertainty about government policy and stock prices. The Journal of Finance, 67(4), 1219-1264. https://doi.org/10.1111/j.1540-6261.2012.01746.x

Peng, H. F., \& Zhu, X. Q. (2019). Multiple arbitrage motives and shock effects of short-term capital flows: Dynamic analysis based on TVP-VAR. Economic Research Journal, 54(8), 36-52.

Phan, D. H. B., Iyke, B. N., Sharma, S. S., \& Affandi, Y. (2021). Economic policy uncertainty and financial stability: Is there a relation? Economic Modelling, 94, 1018-1029. https://doi.org/10.1016/j.economd.2020.02.042

Yang, Z. H., Chen, L. X., \& Chen, Y. T. (2020). Cross-market contagion of economic policy uncertainty and systemic financial risk: A nonlinear network connectedness analysis. Economic Research Journal, 55(1), 67-83.

Zhang, C. S., \& Liu, G. C. (2018). The investing and financing decision mechanism of the Chinese real sector: economic uncertainty and the financial constraints perspective. Economic Research Journal, 53(12), 51-67.

Zhang, X. Y., \& Chen, L. Y. (2019). A study on the Spilover effect and its formation mechanism of economic policy uncertainty. Statistical Research Journal, 36(1), 115-128. 